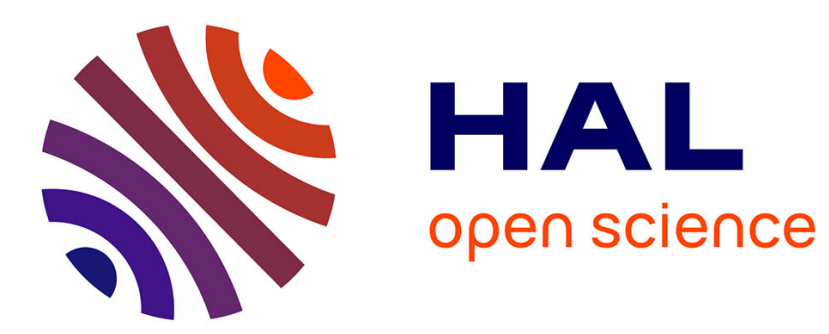

\title{
How cognitive biases can affect the performance of eco-labeling schemes
}

\author{
Antoine Beretti, Gilles Grolleau, Naoufel Mzoughi
}

\section{To cite this version:}

Antoine Beretti, Gilles Grolleau, Naoufel Mzoughi. How cognitive biases can affect the performance of eco-labeling schemes. Journal of Agricultural and Food Industrial Organization, 2009, 7 (2), pp.1-12. 10.2202/1542-0485.1276 . hal-02661877

\section{HAL Id: hal-02661877 https://hal.inrae.fr/hal-02661877}

Submitted on 30 May 2020

HAL is a multi-disciplinary open access archive for the deposit and dissemination of scientific research documents, whether they are published or not. The documents may come from teaching and research institutions in France or abroad, or from public or private research centers.
L'archive ouverte pluridisciplinaire HAL, est destinée au dépôt et à la diffusion de documents scientifiques de niveau recherche, publiés ou non, émanant des établissements d'enseignement et de recherche français ou étrangers, des laboratoires publics ou privés. 


\title{
Journal of Agricultural \& Food Industrial Organization
}

Volume 7 2009 Article 10

SPECIAL ISSUE:

Quality Promotion through Eco-Labeling

\section{How Cognitive Biases Can Affect the Performance of Eco-Labeling Schemes}

\author{
Antoine Beretti $^{*} \quad$ Gilles Grolleau ${ }^{\dagger}$ \\ Naoufel Mzoughi
}

*INRA, beretti@ supagro.inra.fr

†INRA, grolleau@supagro.inra.fr

‡INRA, nmzoughi@avignon.inra.fr

Copyright (c)2009 The Berkeley Electronic Press. All rights reserved. 


\title{
How Cognitive Biases Can Affect the Performance of Eco-Labeling Schemes*
}

\author{
Antoine Beretti, Gilles Grolleau, and Naoufel Mzoughi
}

\begin{abstract}
Individuals exhibit systematic cognitive biases which make their behavior 'deviant' when compared to the benchmark of perfectly rational individuals. The person's tendency to make errors in judgment based on cognitive factors, are thought to be based upon heuristics and lead to decisions that are sub-optimal. Ignoring cognitive biases can affect diverse dimensions of ecolabeling policies and lead to flawed prescriptions. We review several cognitive biases that affect eco-labeling related behaviors and show how taking them into account allows a better understanding of eco-labeling schemes and informs policy makers in order to design and implement more effective eco-labeling policies.
\end{abstract}

KEYWORDS: cognitive biases, eco-labeling

${ }^{*}$ The authors are grateful to the participants of the $2^{\text {nd }}$ International Workshop at Laboratory of Forest Economics (June 29-30, 2009 - Nancy, France) for their useful comments. The authors are also grateful to an anonymous referee and to the editor of the Journal of Agricultural and Food Industrial Organization. 


\section{Introductive remarks}

Eco-labeling schemes provide consumers with information about the environmental impacts of products. As such, most of the economic literature devoted to eco-labeling schemes has analyzed their potential to attenuate informational asymmetry (e.g., Caswell and Mojduszka, 1996; Teisl and Roe, 1998; McCluskey, 2000), allow quality differentiation (e.g., Amacher et al., 2004; Crespi and Marette, 2001) or provide privately public goods (Kotchen, 2005; 2006; Caswell and Grolleau, 2006). Other contributions have emphasized the strategic use of eco-labeling schemes, especially to disadvantage rivals (Körber, 1998; Grolleau et al., 2007). Nevertheless, except some recent contributions (e.g., Bougherara et al., 2005) these studies have neglected an important aspect of human behavior, namely cognitive biases or distortions in the way people perceive reality. We contend that several biases are systematic and ignoring them can reduce the overall effectiveness of eco-labeling schemes. We investigate how cognitive biases (often studied for how they affect other business and economic decisions) influence eco-labeling related decisions and behaviors. We examine how integrating cognitive biases in the analytical framework can improve the understanding of eco-labeling programs and indicate ways of enhancing ecolabeling schemes effectiveness frequently by considering low-cost interventions.

The remainder of this exploratory paper is organized as follows. Each of the four following sections presents and defines a specific cognitive bias, emphasizes its implications to eco-labeling schemes and provides supporting anecdotal evidence. We emphasize a variety of small, low-cost interventions that could have first-order effects on the performance of eco-labeling schemes. The last section summarizes the whole contribution, suggests some orientations for further research and concludes.

\section{The loss aversion bias}

Casual observations show that losses from a reference point have a greater impact upon choices than the equivalent sized gain from the same reference point. Loss aversion means that people are more motivated to avoid losses than to acquire gains. Kahneman et al. (1990) conducted a now famous experiment to test this loss aversion bias. Half the students in a class were randomly given coffee mugs with the insignia of their university embossed on it. Markets for the mug are then conducted by inviting mug owners to sell their mugs and non-owners to buy them. They do so by asking the question: 'At each of the following prices, indicate whether you would be willing to (give up your mug/buy a mug).' The results show that the subjects with mugs demand roughly twice as much to give up their mug as others are willing to pay to get one. This resulted in an unexpectedly low 
volume in trade, in contradiction with the Coase theorem predicting that half the mugs would be traded. Later, the authors conducted a similar market with induced-value tokens. The volume in trade in this market corresponded to the theoretical prediction, supporting the insight that the transaction costs are not responsible of the gap between the predicted and observed volumes on the consumption good (e.g., coffee mugs) market. In another experiment, half the students in a class received coffee mugs and half got large chocolate bars. The mugs and the chocolate cost about the same, and in pretests students were as likely to choose one as the other. Yet when offered the opportunity to switch from a mug to a candy bar or vice versa, only one in ten switched. The authors have conducted a large number of replications of those experiments, but the results are nearly always the same. In sum, people are more reluctant to give up a good they already own rather acquiring the same good if they do not own it previously. Loss aversion is frequently used to explain at least partially the observed disparity between willingness to accept (WTA) and willingness to pay (WTP) (Tversky and Kahneman, 1991).

A major implication of this literature is that all environmental benefits are not equal in consumers' mind. Some products are more likely to be subject to loss aversion than others. For example, people can be motivated to buy organic products because they perceive them as delivering something (health benefits) they already own. If the environmental benefits delivered by some eco-labeled goods are perceived by consumers as a way not to lose something they already have, they will be more likely to purchase these eco-labeled goods. Consequently, eco-labels' designers can attempt to use or induce a 'relationship' between the environmental benefits delivered by the eco-labeled goods (e.g., preserving the local environment that the consumers enjoy rather than remote and unknown environment). For example, it has been reported that the success of the dolphinsafe label on caned tuna in the USA was partly due to the emotional relationship between Americans and dolphins (Körber, 1998; Reinhardt, 2000; McGrory, 2003). In the same vein, framing adequately the eco-label message can influence the reference point used by consumers and play a strong role in improving effectiveness of eco-labeling schemes. According to Martin (2007), 'for messages to have the best chance of being effective it would seem that not only should they be framed in terms of what we stand to lose. That loss should be something we currently possess and should also be accompanied with a clear and specific action we can personally take to avoid such as loss. Not lots of actions just one or two easy, clearly stated, specific and personal ones.' (Martin, 2007; see also Grankvist et al., 2004) 


\section{The attribution bias}

People make systematic and often biased inferences about the causes of events and behavior, and, these attributions strongly influence the way people interact with others (Forsyth et al., 1981; Burger and Rodman, 1983). A traditional distinction in the attribution literature is whether people infer that an event or the behavior of an individual is due to personal factors such as abilities, traits (internal attribution) or to situational factors (external attribution). Causal attributions are important mediators of future behavior because once a cause is assigned, a commensurate action can be taken. The fundamental attribution error describes the people tendency to underestimate external influences when explaining other people's errors whereas they are very likely to look to the situation to explain their own errors. A related bias strongly debated in the audit literature is the self-serving bias where people tend to arrive at judgments of what is fair or right that are biased in the direction of their own self-interests (Babcock and Loewenstein, 1997). For example, Babcock et al. (1996) looked at pay negotiations for public school teachers in Pennsylvania. To decide on a pay settlement, the union and the school board would each look for "comparable" districts to decide what amount is fair. As expected, the research shows that unions were biased towards high pay settlements and employers towards low settlements.

Introducing eco-labeling schemes in the marketplace can be analyzed as a strategy to build a causality relationship between consumers' choices and environmental outcomes. Eco-labeling schemes help consumers to vote with their wallet. Indeed, either the consumer contributes to a better environment by purchasing preferentially eco-labeled products or contributes to an increase (or no decrease) of pollution through the purchase of more polluting products. Consequently, the eco-labeling schemes attempt to make consumers partly responsible of the state of the environment through their purchase decisions. ${ }^{1}$

A major implication for eco-labeling schemes relates to the causes to which consumers attribute the state of the environment and the responsibility of doing something to fix a potential problem. Indeed, if most consumers attribute the state of the environment and the responsibility of doing something to other groups (e.g., firms, public authorities, environmental groups), individuals can feel

\footnotetext{
${ }^{1}$ Interestingly, Ruffieux (2004) argues that the preexisting intrinsic pro-environmental motivation among consumers can be to some extent reduced ex post because of market interactions per se. This is notably due to a motivational crowding-out where market interactions exacerbate extrinsic motivations such as monetary incentives opposed to intrinsic motivation, such as altruism (Reeson, 2008). So eco-labeling schemes can both increase the consumer self-attribution in certain environmental outcomes and generate subsequent actions while undermining to some extent proenvironmental motivation among consumers because it uses market interactions per se to promote environmentally friendly behaviors.
} 
themselves less concerned and less likely to purchase eco-labeled products. An empirical strategy can be to test on survey data whether people that attribute environmental degradation or responsibility of doing something to external forces are more or less likely to undertake pro-environmental behaviors such as purchasing eco-labeled products. To overcome this passivity, a strategy can be to increase the degree of internal attribution among potential consumers of eco-labeled products.

Another relevant distinction that goes beyond the external versus internal attribution is currently debated in the literature. Both economists and psychologists have challenged the classical interpretation of the outcomes of environmental valuation studies, in which utility is a function of outcomes or consequences only. They have emphasized the importance of the attributes of the choice being made and have provided evidence that people are willing to pay more to solve an environmental problem if they think it is man-caused than if they think it is caused by nature (Kahneman et al., 1993; Kahneman and Ritov, 1994; DeKay and McClelland, 1996; Brown et al., 2002). This is referred to as the 'outrage effect' (Kahneman et al., 1993). In opposition with these results, Walker et al. (1999) challenge the hypothesis that people are willing to contribute more to undo man-made disasters than natural ones. They find the opposite result in their study - WTP to undo harm caused by humans was lower than WTP for natural damages - and they therefore hypothesize that the WTP is driven by the degree of responsibility that people feel for the damages ('responsibility effect'). Building on this, Bulte et al. (2005) conducted an interesting field study in the Netherlands. They tested for two types of attribution, natural and human-caused, and they distinguished between two types of human causes: global warming, where society at large is responsible, and drilling for oil and gas, where industry causes the damage. They found evidence supporting the 'outrage effect' but no evidence supporting the 'responsibility effect'.

Moreover, the debate regarding the impossibility of auditors to remain impartial and objective because of the self-serving bias (Bazerman et al., 1997) seems useful to go beyond explanations based on asymmetric information and improve the understanding of certification practices in the environmental realm. In short, when making judgments, 'people tend to confuse what is personally beneficial with what is fair or moral'. Psychological research shows that the self serving bias 'enters unconsciously and unintentionally (emphasis added) at the stage of making judgments, not of reporting on them, although there may be some deliberate misreporting as well' (Bazerman et al., 1997, p. 91). The nondeliberateness of misrepresentation implies that threat of sanctions will have a limited effectiveness. This self-serving bias can be exacerbated by several characteristics of the certifying process, such as 'known victims', immediate negative consequences of a negative opinion, ongoing relationships and 
consulting and auditing by entities that are dependant (Bazerman et al., 1997). In sum, users of the third party certification need to pay greater attention to this pervasive bias.

\section{The optimism bias}

The optimism bias describes the tendency of people to be over-optimistic about their own behavior compared to others' behavior. A familiar illustration of this bias is that most people think that their chances of having a car accident are significantly lower than the average person's chances of experiencing this event (DeJoy, 1989). Nevertheless, if every individual is better than average, then the average will be different. For example, if every individual considers he purchases more eco-labeled products than the average consumer, then the 'average' consumption of eco-labeled products would be higher. A direct consequence is that every individual can expect that others will undertake efforts, given that he is himself above average, feeling that he is doing better than others. It is possible that when informed about his real level of contribution (compared to others) in a given field, the individual can be more likely to behave as expected.

An interesting field experiment achieved in California (Schultz et al., 2007) supports these insights. The authors showed that when the monthly electric bill listed the average consumption in the neighbourhood, the people in aboveaverage households significantly decreased their consumption. At the same time the people with the below-average bills reacted by significantly increasing their consumption. To avoid this unanticipated reaction, they added a little drawing along with the numbers: a smiling face on a below-average bill or a frowning face on an above-average bill. They labelled this effect the 'injunction effect'. The heavy users achieved bigger reduction in electricity consumption, while the light users remained frugal.

In sum, helping people to locate objectively themselves in comparison to others by indicating the true 'average' can de-bias the behavior by reducing the perceived social distance between the self and the typical consumer. Interestingly, de-biasing individuals in this area shares features with conformity to social norms (see Cialdini, 2005; Nyborg et al., 2006). This insight is relevant especially when the eco-label designer can target subgroups whose contribution is less than the true average but think they are above. An empirical strategy to investigate the optimism bias can be implemented by asking people to position themselves on different environmental domains (e.g. recycling, purchase of eco-labeled products, etc.) and compute a stated average that can be compared to the objective average of the group considered. Other treatments can explore how information provision on the 'true' average influences people's perception of their own efforts. 


\section{The cognitive dissonance}

Cognitive dissonance is an uncomfortable psychological state resulting from an inconsistency between attitudes and behaviors. The individual is motivated to do something in order to relieve this tension. To relieve the cognitive dissonance, the individual should, in theory, (i) either change his behavior such that it becomes consistent with his attitudes, or (ii) change his attitudes, or (iii) expose himself to selective information that 'makes' his behavior becoming consonant. Related to the last point, individuals can find beneficial to remain ignorant to avoid a state of cognitive dissonance (bliss ignorance). Some authors have emphasized the potential of integrating the cognitive dissonance in the economic reasoning (e.g., Akerlof and Dickens, 1982; Rabin, 1994).

Several insights regarding eco-labeling schemes can be drawn from the cognitive dissonance theory. Arousing a state of cognitive dissonance thanks to an eco-label can push people to behave in the expected direction. The cognitive dissonance can also explain why people ignore even free and credible information that allow them to behave according to their stated preferences. For example, Frank (2006) shows with a simple model that people can increase their net utility by ignoring information about process attributes. The case of the dolphin-safe tuna label can illustrate an unintended effect of information on the consumer net utility. Let us consider an ignorant consumer enjoying a utility gain of $U_{t}$ from a unit of tuna consumption at the cost of buying the tuna whose production cost is $\mathrm{C}_{1}$.

$$
\mathrm{U}_{\text {net } 0}=\mathrm{U}_{\mathrm{t}}-\mathrm{U}\left(\mathrm{C}_{1}\right)
$$

A tuna supplier then decides to launch a new label: the dolphin-safe tuna label. He is thus adding the cost of a dolphin-safe technology to his production costs. At the same time, he provides a new knowledge to our presumably dolphinfriendly consumer: the unlabeled tuna uses technology that kills dolphins. As a consequence, the consumer experiences a state of cognitive dissonance as he suffers an additional loss in utility of $U_{k}$ when consuming the same unit of dolphin-killing tuna. Once informed on catching tuna technologies, the consumer has three alternatives:

- he keeps consuming dolphin-killing tuna

$$
\mathrm{U}_{\text {net } 1}=\mathrm{U}_{\mathrm{t}}-\mathrm{U}_{\mathrm{k}}-\mathrm{U}\left(\mathrm{C}_{1}\right)
$$

- he switches to dolphin-safe tuna 
$\mathrm{U}_{\text {net2 }}=\mathrm{U}_{\mathrm{t}}-\mathrm{U}\left(\mathrm{C}_{2}\right)$

- he stops consuming tuna

$\mathrm{U}_{\text {net3 }}=0$

Assuming $\mathrm{U}_{\mathrm{k}}>0$ and $\mathrm{C}_{1}<\mathrm{C}_{2}$, the consumer maximizes his net utility by making an optimal choice depending on whether $\mathrm{U}\left(\mathrm{C}_{2}\right)-\mathrm{U}\left(\mathrm{C}_{1}\right)>\mathrm{U}_{\mathrm{k}}$ and whether $\mathrm{U}_{\text {net1 }}$ and $\mathrm{U}_{\text {net2 }}$ are greater than 0 .

- If $\mathrm{U}_{\text {net1 }}>0$ and $\mathrm{U}\left(\mathrm{C}_{2}\right)-\mathrm{U}\left(\mathrm{C}_{1}\right)>\mathrm{U}_{\mathrm{k}}$, the individual keeps consuming dolphin-killing tuna, experiencing a reduced utility $\mathrm{U}_{\text {net1 }}$ when compared to the utility $\mathrm{U}_{\text {net0 }}$ of the 'ignorant' benchmark state.

- If $U_{\text {net2 }}>0$ and $U\left(C_{2}\right)-U\left(C_{1}\right)<U_{k}$, the individual switches to dolphinfriendly tuna, experiencing a reduced utility $\mathrm{U}_{\text {net2 }}$ when compared to the utility $\mathrm{U}_{\text {net0 }}$ of the 'ignorant' benchmark state.

- If $\mathrm{U}_{\text {net2 }}<0$ and $\mathrm{U}_{\text {net1 }}<0$, the individual stops consuming tuna, experiencing $\mathrm{U}_{\text {net3 }}=0$.

As a consequence, regardless of the selected option, the utility received is necessarily less than the utility experienced through the consumption of tuna when the individual remains ignorant. The individual can prefer a "bliss ignorance' state. According to Ehrich and Irwin (2005), a consumer can be better off by ignoring information to avoid a cognitive dissonance state and even support producers that do not make public 'cognitive dissonance'-inducing information.

A related perverse effect can result from the fact that firms (motivated by profit maximization) encourage people to relieve a state of cognitive dissonance through the purchase of a given eco-labeled good. While the beneficial impact on the environment is true, let us suppose that it is also small compared to another domain. For example, an individual, thanks to an eco-label, can make an effort to purchase aerosols emitting less greenhouse gazes and relieves a state of cognitive dissonance. At the same time, the most significant effort for reducing greenhouses gazes emission at the individual level relates to car use. The individual can feel himself consonant (and even stop feeling guilty) because of his small effort, which is objectively a 'tree that hides the forest' ${ }^{2}$ (Pettit and Sheppard, 1992). Indeed, the individual will purchase a kind of moral satisfaction at a very low

${ }^{2}$ This point is related to a recent contribution of Kotchen (2009) about whether voluntary carbon offsets help counteract greenhouse gases, or are just a way for guilt-ridden consumers to buy their way out of bad feelings. 
cost. The overall result can be an environmental degradation rather than an improvement.

Lastly, if preferences adapt to behaviors rather than the other way around (endogenous preferences), one can consider changing consumers' preferences as an instrument of environmental policy tool that can be used to encourage more environmentally friendly consumption choices (Norton et al., 1998).

\section{Concluding remarks}

We have briefly examined how psychological findings can usefully inform the design and implementation of eco-labeling policies. Indeed, systematic biases can prevent people from behaving as predicted and can explain unanticipated results. For sake of simplicity and exposition, we have examined independently some cognitive biases, while they frequently interact in real-life contexts. For example, attribution bias or optimism bias can help an individual to avoid a state of cognitive dissonance. For example, a dolphin-killing canned tuna consumer can avoid a state of cognitive dissonance by considering that (i) the producer is responsible of killing dolphins and (ii) he is already doing better than the average consumer in the society for environmental concerns. Several other biases have not been investigated such as the positional bias and the relation between status seeking and cognitive dissonance (Oxoby, 2004). Moreover, the issue of the interaction between behavioural biases and 'traditional economic behavior' has not been addressed. For example, according to Östling (2009) a change in price and income can lead to an increase in consumption of 'immoral goods', by increasing the moral value of these goods. Therefore an eco-label production policy (i.e. choice of price and quantity) can have an effect on the eco-label moral value, and thereby on the consumption level of eco-labeled goods.

Many traditionally educated economists may perhaps be sceptical about the content and purpose of our contribution. Nevertheless, we contend that ignoring these biases can lead to flawed prescriptions and that small and low-cost interventions can contribute to de-bias individuals in a socially desirable way. We are aware that the alternative models of individual behavior have only been alluded to. Integrating the behavioral dimension is a very promising issue, capable of complementing more traditional research and generating high net returns. 


\section{References}

Akerlof, G., and W. Dickens. "The Economic Consequences of Cognitive Dissonance." American Economic Review 72(1982):307-319.

Amacher, G., E. Koskela, and M. Ollikainen. "Environmental Quality Competition and Eco-labeling." Journal of Environmental Economics and Management 47(2004):284-306.

Babcock, L., and G. Loewenstein. "Explaining Bargaining Impasse: The Role of Self-Serving Biases." Journal of Economic Perspectives 11(1997):109126.

Babcock, L., X. Wang, and G. Loewenstein. "Choosing the Wrong Pond: Social Comparisons in Negotiations that Reflect a Self-Serving Bias." Quarterly Journal of Economics 111(1996):1-19.

Bazerman, M.H., K.P. Morgan, and G.F. Loewenstein. "The Impossibility of Auditor Independence." MIT Sloan Management Review 38(1997):89-94.

Bougherara, D., G. Grolleau, and L. Thiébaut. "Can Labelling Policies Do More Harm Than Good? An Analysis Applied to Environmental Labelling Schemes." European Journal of Law and Economics 19(2005):5-16.

Brown T.C., D. Nannini, R.B. Gorter, P.A. Bell, and G.L. Peterson. "Judged Seriousness of Environmental Losses: Reliability and Cause of Loss." Ecological Economics 42(2002):479-491.

Bulte, E., S. Gerking, J.A. List, and A. de Zeeuw. "The Effect of Varying the Causes of Environmental Problems on Stated WTP Values: Evidence from a Field Study." Journal of Environmental Economics and Management 49(2005):330-342.

Burger, J.M., and J.L. Rodman. "Attributions of Responsibility for Group Tasks: The Egocentric Bias and the Actor-Observer Difference." Journal of Personality and Social Psychology 45(1983):1232-1242.

Caswell, J.A., and G. Grolleau. "Interaction Between Food Attributes in Markets: The Case of Environmental Labeling." Journal of Agricultural and Resource Economics 31(2006):471-484.

Caswell, J.A., and E.M. Mojduszka. "Using Informational Labeling to Influence the Market for Quality in Food Products." American Journal of Agricultural Economics 78(1996):1248-1253.

Cialdini, R.B. "Basic Social Influence is Underestimated." Psychological Inquiry 16(2005):158-161.

Crespi, J., and S. Marette. "How Should Food Safety Certification Be Financed." American Journal of Agricultural Economics 83(2001):852-861.

Dejoy, D.M. "The Optimism Bias and Traffic Accident Risk Perception." Accident Analysis and Prevention 21(1989):333-340. 
DeKay, M.L., and G.H. McClelland. "Probability and Utility Components of Endangered Species Preservation Programs." Journal of Experimental Psychology 2(1996):60-83.

Ehrich, K., and J. Irwin. "Willful Ignorance in the Request for Product Information." Journal of Marketing Research 42(2005):266-277.

Forsyth, D.R., R.E. Berger, and T. Mitchell. "The Effects of Self-serving vs. Other-Serving Claims of Responsibility on Attraction and Attribution in Groups." Social Psychology Quarterly 44(1981):56-64.

Frank, J. "Process Attributes of Goods, Ethical Considerations and Implications for Animal Products." Ecological Economics 58(2006):538-547.

Grankvist, G., U. Dahlstrand, and A. Biel. "The Impact of Environmental Labelling on Consumer Preference: Negative versus Positive Labels." Journal of Consumer Policy 27(2004):213-230.

Grolleau, G., L. Ibanez, and N. Mzoughi. "Industrialists Hand in Hand with Environmentalists: How Eco-labelling Schemes Can Help Firms to Raise Rivals' Costs." European Journal of Law and Economics 24(2007):215236.

Kahneman, D., J.T. Knetsch, and R.H. Thaler. "Experimental Tests of the Endowment Effect and the Coase Theorem." The Journal of Political Economy 98(1990):1325-1348.

Kahneman, D., and I. Ritov. "Determinants of Stated Willingness to Pay for Public Goods: a Study in the Headline Method." Journal of Risk Uncertainty 9(1994):5-38.

Kahneman, D., I. Ritov, K.E. Jacowitz, and P. Grant. "Stated Willingness to Pay for Public Goods: a Psychological Perspective." Psychological Science 4(1993):310-315.

Körber, A. "Why Everybody Loves Flipper: The Political-Economy of the U.S. Dolphin-Safe Laws." European Journal of Political Economy 14(1998):475-509.

Kotchen, M.J. "Impure Public Goods and the Comparative Statics of Environmentally Friendly Consumption." Journal of Environmental Economics and Management 49(2005):281-300.

Kotchen, M.J. "Green Markets and Private Provision of Public Goods." Journal of Political Economy 114(2006):816-834.

Kotchen, M.J. "Offsetting Green Guilt." Stanford Social Innovation Review 7(2009):26-31.

Martin, S., 2007, No Penguins in My Garden, The Guardian, December, 16, http://www.guardian.co.uk/commentisfree/2007/dec/16/nopenguinsinmyg arden. 
McCluskey, J. "A Game Theoretic Approach to Organic Foods: An Analysis of Asymmetric Information and Policy." Agricultural and Resource Economics Review 29(2000):1-9.

McGrory, M., 2003, All Creatures Great and Small, The Washington Post, February, 2, http://www.washingtonpost.com/wp-dyn/articles/A87792003Jan31.html.

Norton, B., R. Costanza, and R.C. Bishop. "The Evolution of Preferences. Why 'Sovereign' Preferences May Not Lead to Sustainable Policies and What to Do About It." Ecological Economics 24(1998):193-211.

Nyborg, K., R.B. Howarth, and K.A. Brekke. "Green Consumers and Public Policy: On Socially Contingent Moral Motivation." Resource and Energy Economics 28(2006):351-66.

Östling, R. "Economic Influences on Moral Values." The B.E. Journal of Economic Analysis and Policy 9(2009):article 2.

Oxoby, R.J. "Cognitive Dissonance, Status and Growth of the Underclass." Economic Journal 114(2004):727-749.

Pettit, D., and J.P. Sheppard. "It's Not Easy Being Green: The Limits of Green Consumerism in Light of the Logic of Collective Action." Queens Quarterly 99(1992):328-350.

Rabin, M. "Cognitive Dissonance and Social Change." Journal of Economic behavior and Organization 23(1994):177-194.

Reeson, A. "Institutions, Motivations and Public Goods: Theory, Evidence and Implications for Environmental Policy." CSIRO Working Paper Series: Socio-Economics and the Environment in Discussion, CSIRO Sustainable Ecosystems, 2008.

Reinhardt, F.L. Down to Earth: Applying Business Principles to Environmental Management, Boston, MA: Harvard Business School Press, 2000.

Ruffieux, B. "Le nouveau citoyen consommateur: que peut-on attendre en termes d'efficacité économique. " Sciences de la Société 62(2004):93-117.

Schultz, P.W., J. Nolan, R. Cialdini, N. Goldstein, and V. Griskevicius. "The Constructive, Destructive, and Reconstructive Power of Social Norms." Psychological Science 18(2007):429-434.

Teisl, M.F., and B. Roe. "The Economics of Labeling: An Overview of Issues for Health and Environmental Disclosure." Agriculture and Resource Economics Review 28(1998):140-150.

Tversky, A., and D. Kahneman. "Loss Aversion in Riskless Choice: A ReferenceDependent Model." The Quarterly Journal of Economics 106(1991):10391061.

Walker, M.E., O.F. Morera, J. Vining, and B. Orland. "Disparate WTA-WTP Disparities: the Influence of Human versus Natural Causes." Journal of Behavioral Decision Making 12(1999):219-232. 